\title{
PURE NEURITIC LEPROSY PRESENTING WITH TYPE 1 REACTION: A RARE CASE REPORT
}

\author{
Raksha Pathak $^{1}$, Sudha Agrawal ${ }^{1}$, and Punam Paudyal ${ }^{1}$ \\ ${ }^{1}$ BP Koirala Institute of Health Sciences
}

February 23, 2021

\begin{abstract}
Type 1 reaction in pure neuritic leprosy usually occurs in the form of neuritis. Development of new skin lesion during reactional state is rare. The clinicians should be aware about occurrence of Type 1 reaction in pure neuritic leprosy and start timely treatment to prevent further disabilities.
\end{abstract}

\section{Introduction:}

Pure neuritic leprosy as a distinct type of leprosy is recognized only under Indian Association of Leprologist's classification. It includes leprosy cases affecting peripheral nerves without any skin lesions.[1] Type 1 reactions (reversal reactions) in leprosy patients present as increased inflammation of preexisting lesions, appearance of new erythematous lesions, facial and pedal edema and even neuritis.[2] Occurrence of type 1 reaction is not common in pure neuritic leprosy. Whenever it occurs, it usually manifests as increased intensity of neuritis and nerve function impairment. However, new skin lesion as manifestation of reactional state is unusual. [3] We present a case of an adult female diagnosed with pure neuritic leprosy, who later developed type 1 reaction in the form of neuritis, pedal edema and appearance of erythematous and edematous new skin lesion over the left cheek. Type 1 reaction was confirmed by histopathology and patient was successfully managed with WHO MB-MDT and oral corticosteroids.

\section{Case report:}

A 36 years old lady presented with ulcer over anterolateral aspect of left foot (figure 1a) for duration of 8 months. She was diagnosed as leprosy from other center and was started on WHO MB-MDT blister pack. She was under fifth blister pack at the time of presentation to our center. She had history of decreased sensation over bilateral hands and feet but there was no history of any cutaneous lesions of leprosy.

Clinical examination showed thickened and non-tender peripheral nerves (ulnar, radio cutaneous and lateral popliteal) with complete loss of sensation to temperature (hot/cold), touch and pain over bilateral hands and feet as per WHO testing sites. There was hypothenar atrophy on right hand and mobile clawing of little finger on left hand. No cutaneous lesions suggestive of leprosy were noted.

Slit skin smear was negative. Nerve conduction study revealed asymmetrical sensory-motor axonal polyneuropathy involving peripheral nerves of upper limbs and symmetrical sensory involvement on nerves of lower limbs. The diagnosis of Pure Neuritic Hansen's Disease with grade II disability of bilateral hands and left foot and grade I disability of right foot was made and patient was continued WHO MB-MDT with immobilization of feet and closed dressing of trophic ulcer. The ulcer was healed completely in 4 weeks. (Figure 1b) 


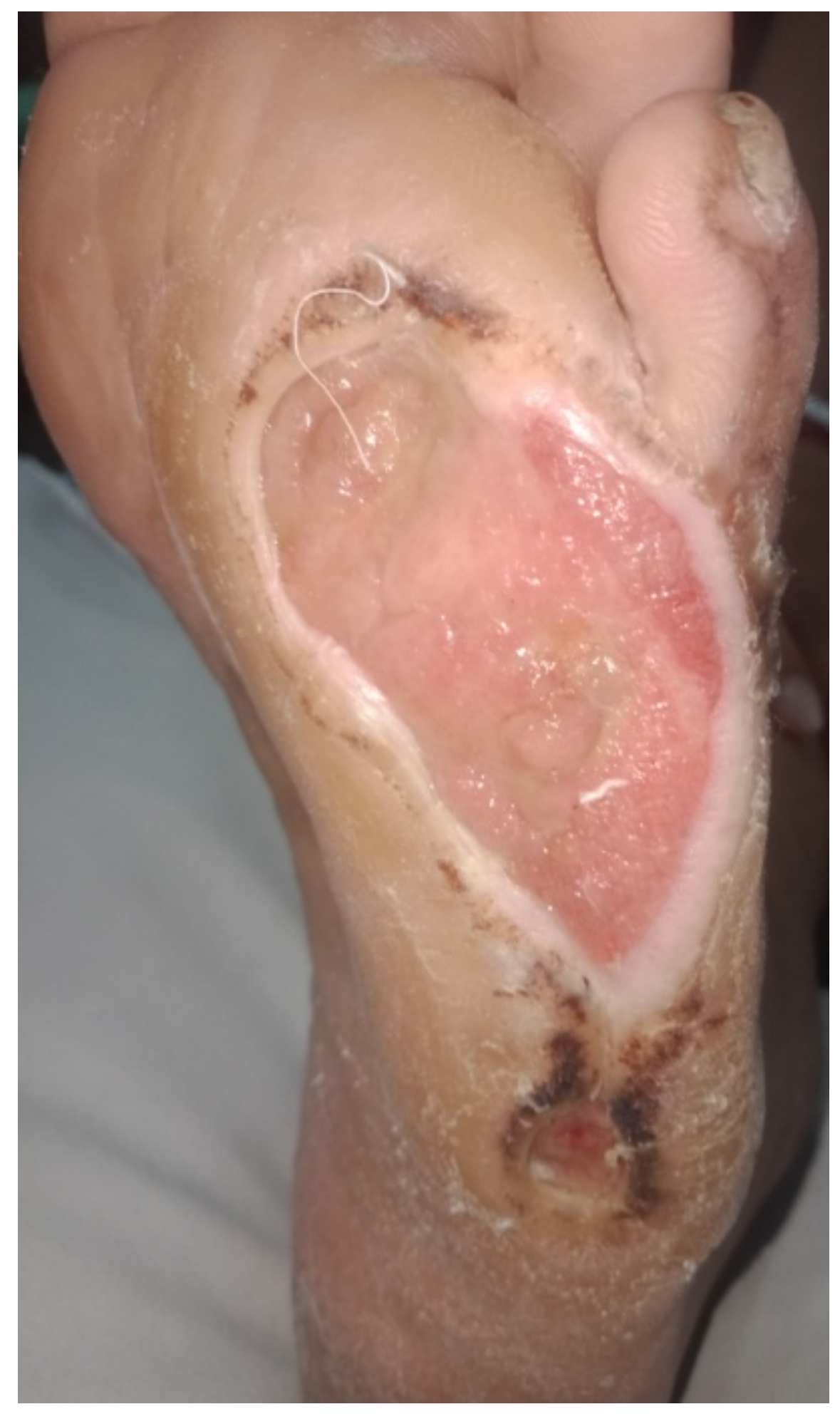




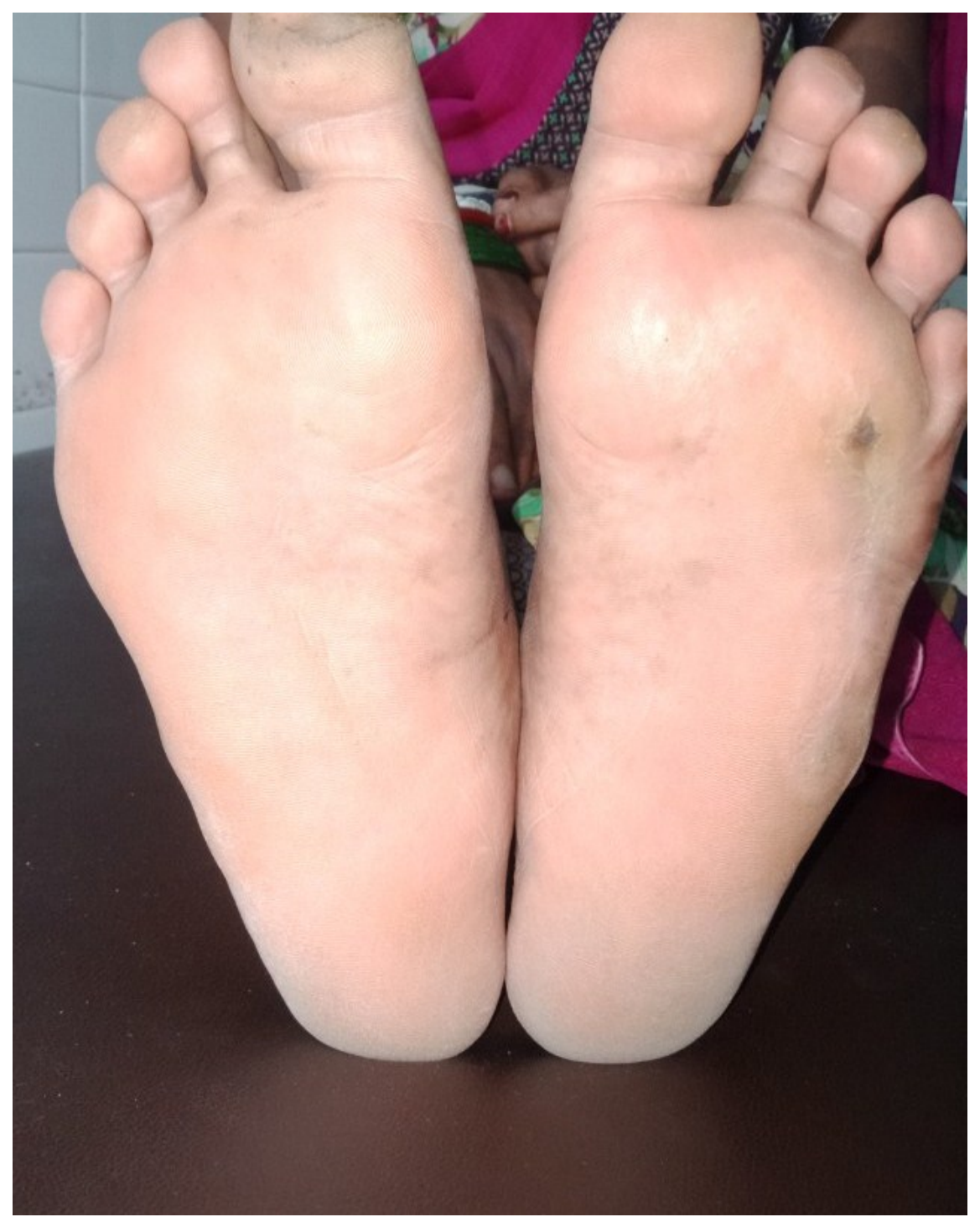

Three months later, patient developed acute onset swelling of bilateral legs associated with tingling sensation disturbing daily activities. There was presence of pitting edema over bilateral feet extending till distal onethird of legs (figure 2a). Similarly, erythematous edematous area was noticed over left cheek. (figure 2b) 


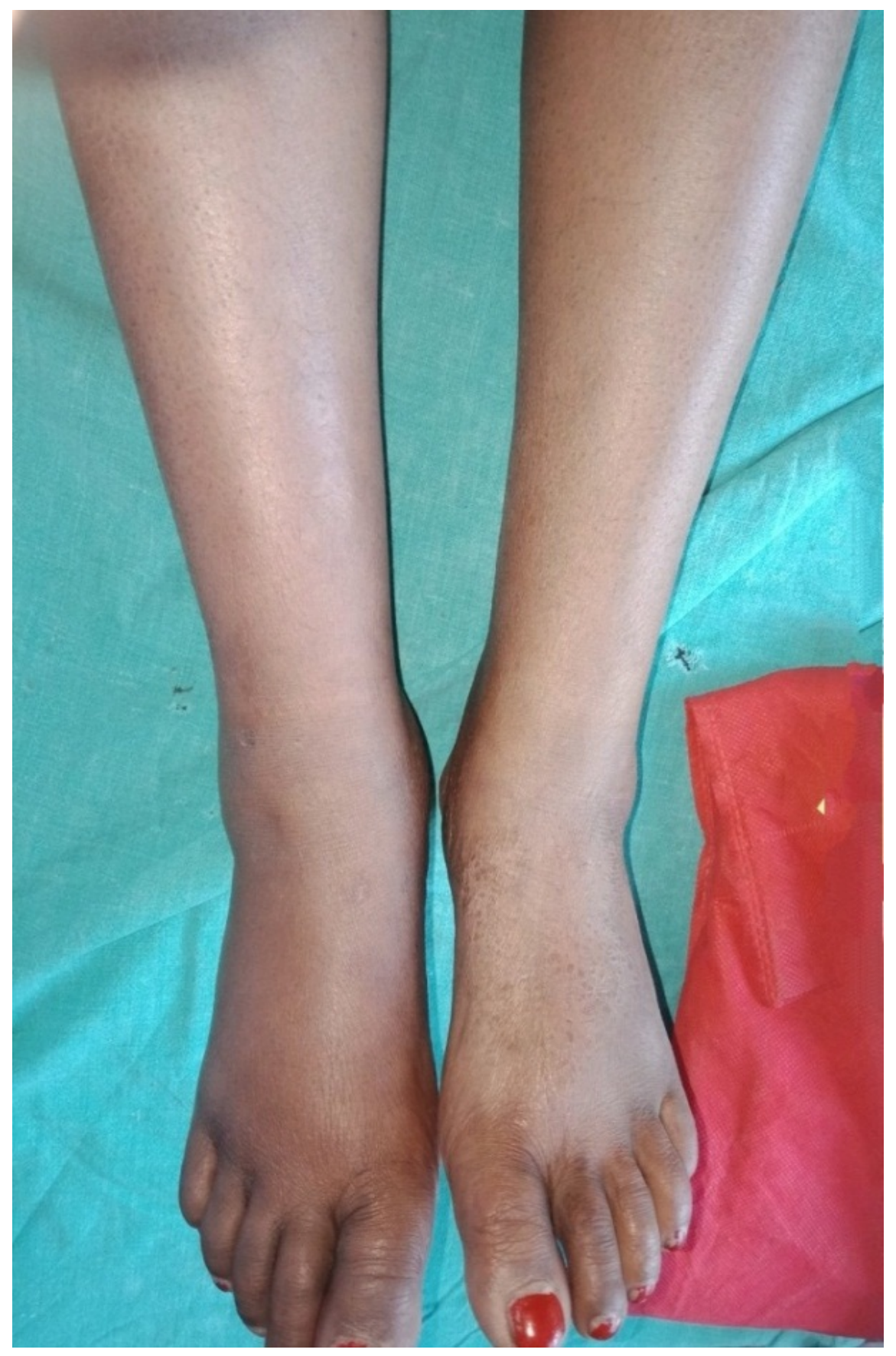




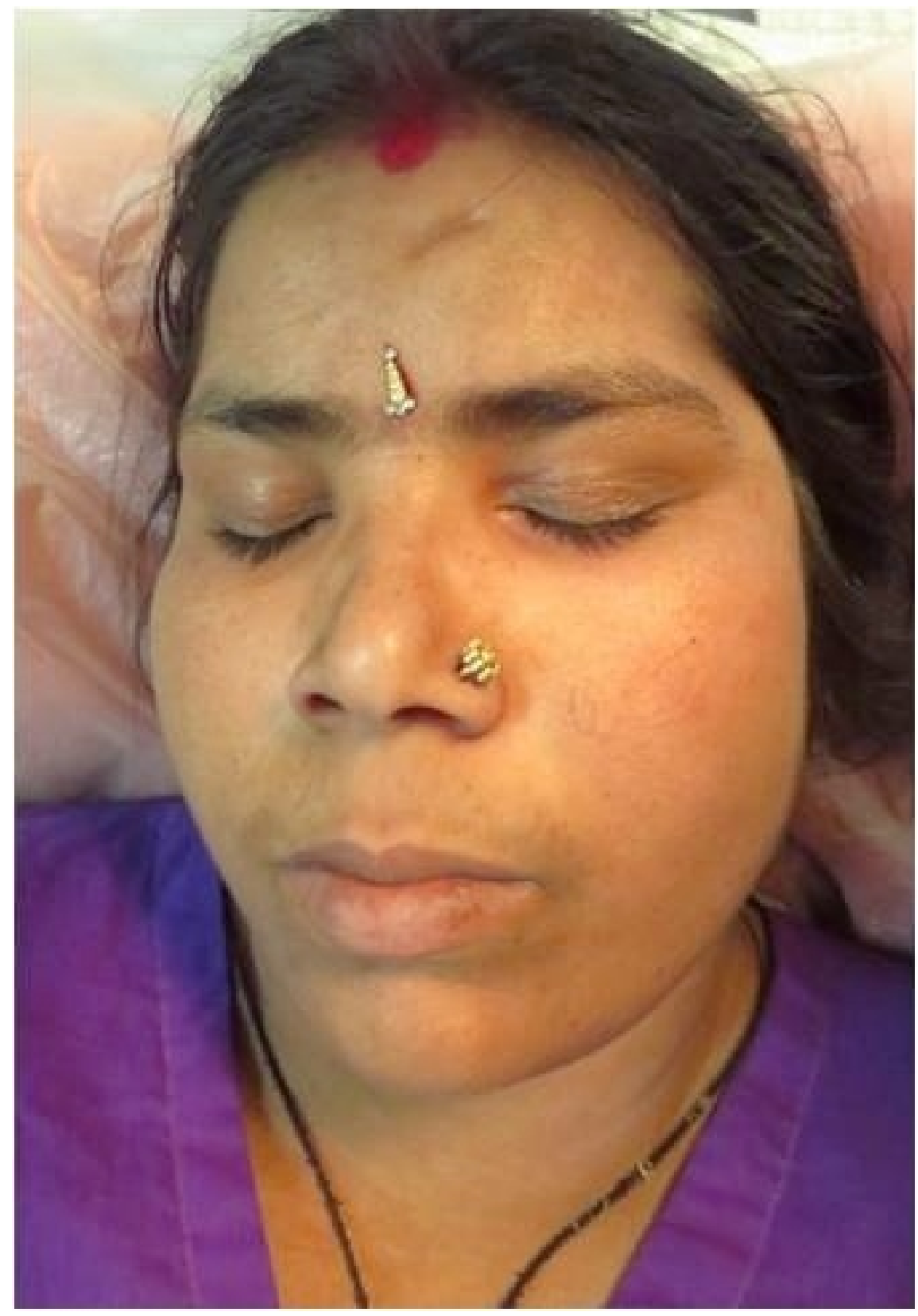

The clinical diagnosis of lepra type 1 reaction was confirmed by examination of biopsy specimen taken from two sites, face and leg, which showed edematous dermis with perivascular, periadnexal and interstitial lymphohistiocytic infiltrate along with few epitheloid histiocytes. The infiltrates were encroaching the arrector pili muscles and destructing nerve bundles. Stain for acid fast bacilli (lepra) was negative. (figure 3a,b,c) 


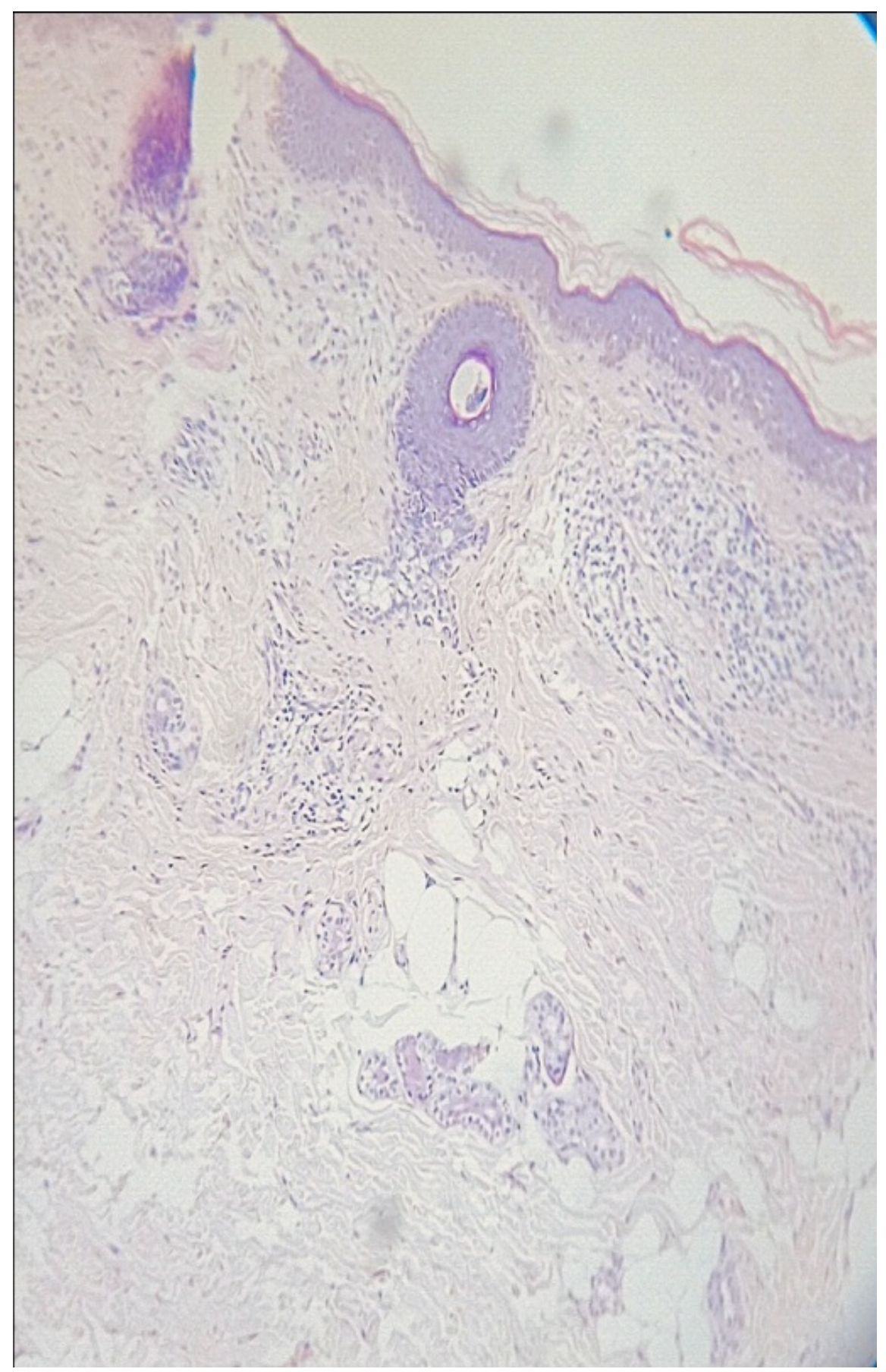



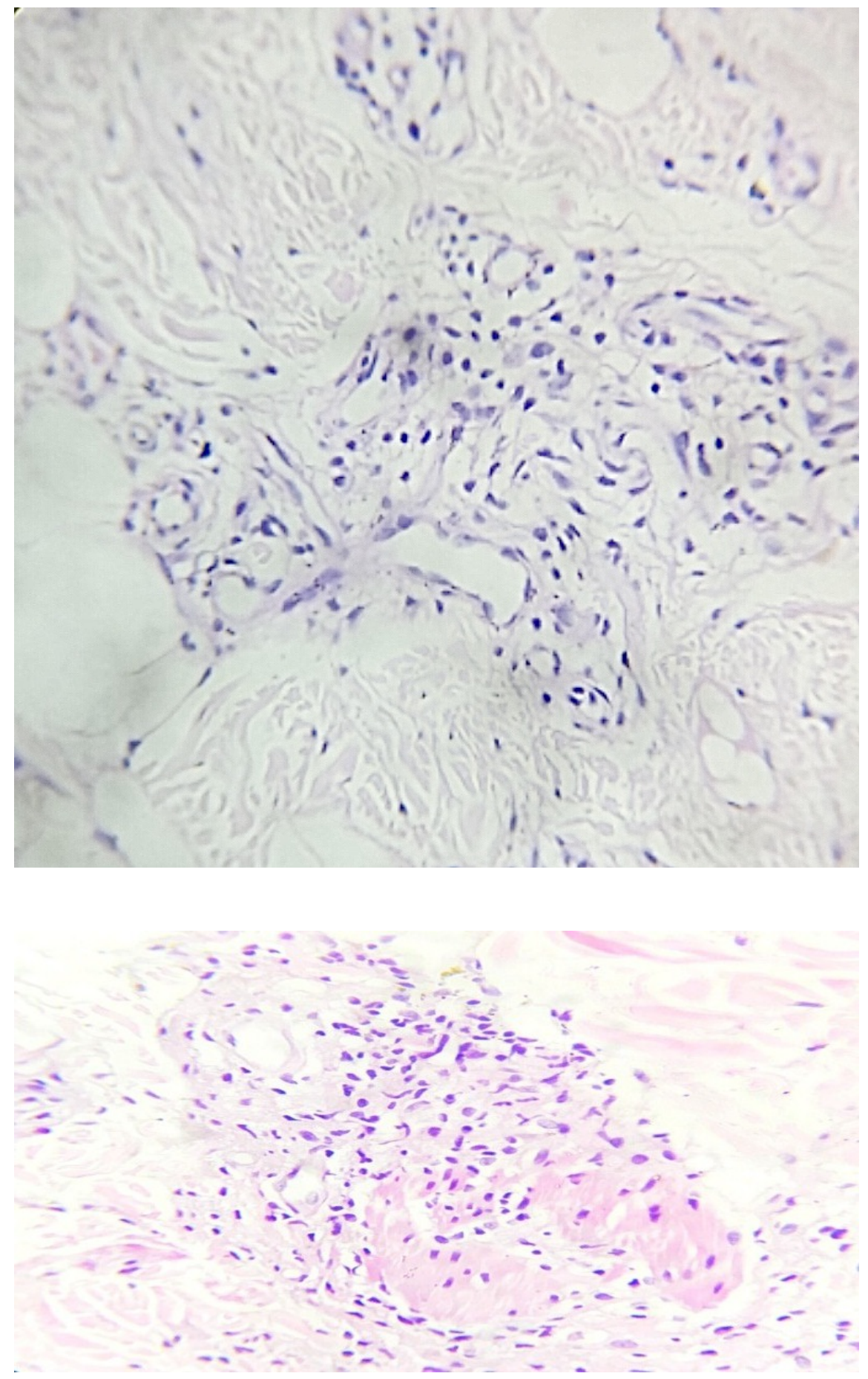

Erythema and edema over left cheek and edema on bilateral legs improved considerably after 2 weeks of starting oral prednisolone $40 \mathrm{mg}$ following which dose of corticosteroid was tapered slowly. The pedal edema subsided (figure 4a) and the erythematous plaque over the left cheek resolved (figure4b) in 8 weeks and after 30 weeks of treatment with tapering dose of oral corticosteroid, steroid was stopped. The patient completed 24 blister pack of WHO MB-MDT. 



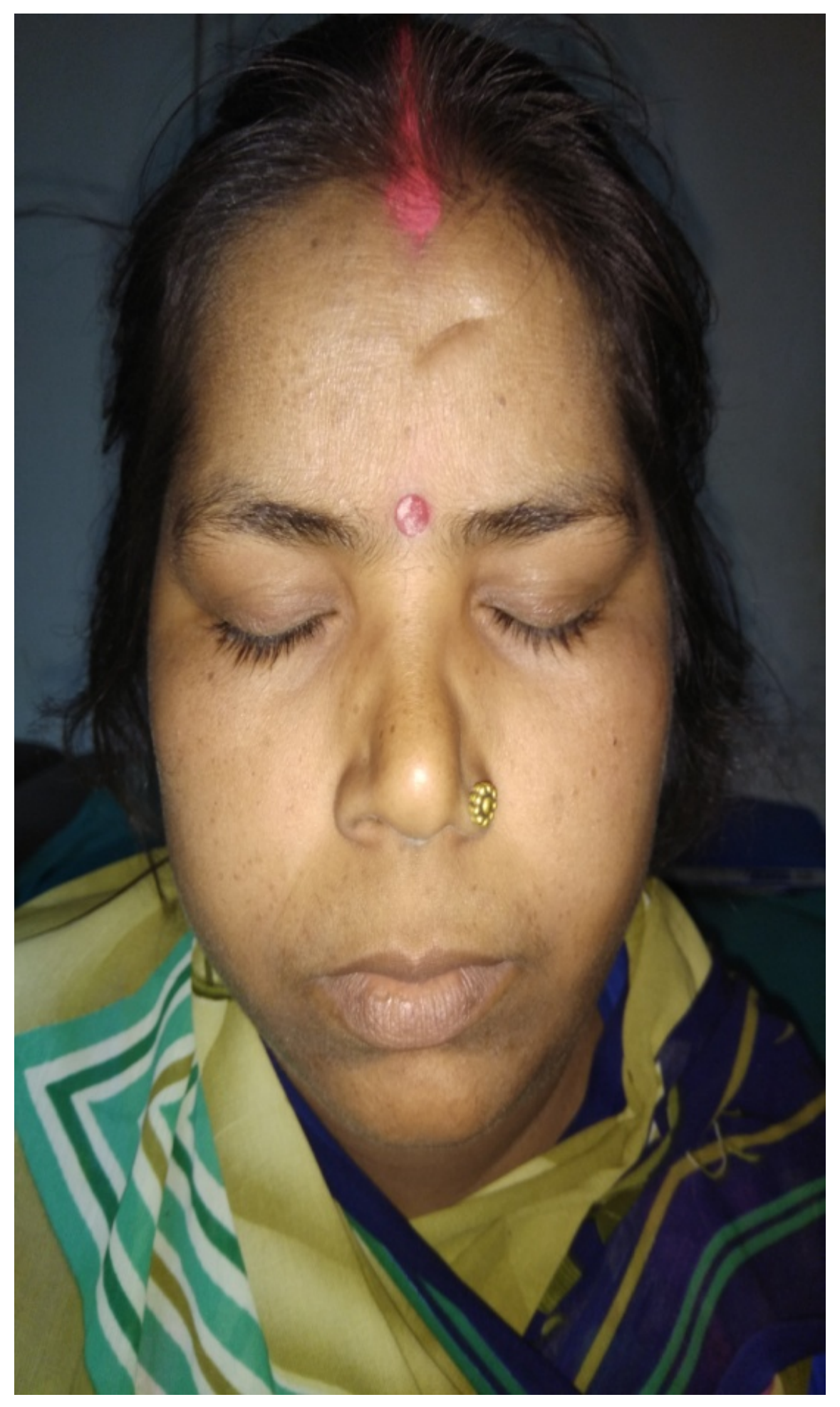

\section{Discussion:}

Pure neuritic leprosy is an uncommon presentation of leprosy. However, in Indian subcontinent, 4.6-17.7\% of leprosy patients present with nerve involvement without skin lesions [4]. Sensory, motor and/or autonomic 
deficit occurs along the distribution of the affected nerve.[5] Ulnar nerve and lateral popliteal nerve are the most common nerves involved in upper limbs and lower limbs respectively, though, any nerve can be involved [3].They are frequently misdiagnosed because of absence of skin lesions and negative slit skin smear and can present with Grade II disability as initial presentation [6]. Nerve biopsy is the gold standard for diagnosis but it is an invasive procedure with possible complications like nerve damage. The non-invasive high quality electrophysiological studies are helpful in the diagnosis of leprosy. [7]

On follow up, 15-35\% of pure neuritic leprosy patients develop visible skin lesions which may indicate prolonged neuritic phase preceding the appearance of cutaneous lesions and most of these lesions are confirmed as borderline tuberculoid type histopathologically [8-11]. Sudden appearance of new lesions can occur due to fluctuations of cell mediated immunity in untreated or treated cases of leprosy. Some authors considered that the new skin lesions developed were possibly manifestation of reversal reaction [9-12]. Absence of visible skin lesions in patients is probably related to the deep location of granuloma in the dermis which could be manifested during reactions. This is yet to be proven. Due to absence of preexisting lesions to manifest inflammatory process, the diagnosis of type 1 reaction in pure neuric leprosy is often missed, under-recorded and under-reported [3].

In our patient, the diagnosis of pure neuritic leprosy was made by clinical examination performed by an experienced clinician combined with nerve conduction studies and the type 1 lepra reaction by increased tingling sensation with the development of edematous and erythematous new lesion over left cheek and pedal edema. This was correlated histopathologically with biopsy from these sites and resolution of pedal edema and lesion over the cheek after administration of oral corticosteroids. The clinicians should be aware about unusual presentation of type 1 reaction in pure neuritic leprosy so that unnecessary work-ups are avoided and disabilities are prevented.

\section{References:}

1. Cinical histopathological and immunological features of the five type classification approved by the Indian association of leprologists. Lepr India 1982;54:22-5.

2. Nery JA, Bernardes Filho F, Quintanilha J et al. Understanding the type 1 reactional state for early diagnosis and treatment: a way to avoid disability in leprosy. An Bras Dermatol. 2013;88(5):787-792.

3. Rao P N, Suneetha S. Pure neuritic leprosy: Current status and relevance. Indian J Dermatol Venereol Leprol 2016;82:252-61

4. Kumar B, Kaur I, Dogra S, Kumaran MS. Pure neuritic leprosy in India: An appraisal. Int J Lepr Other Mycobact Dis 2004;72:284-90

5. Van Brakel WH, Khawas IB. Silent neuropathy in leprosy: an epidemiological description. Lepr Rev 1994;65:350-360.

6. Kumar B. Pure or Primary neuritic Leprosy (PNL) Lepr Rev 2016: 87; 450-455

7. Jardim MR, Antunes SL, Santos AR, Nascimento OJ, Nery JA, Sales AM, et al. Criteria for diagnosis of pure neural leprosy. J Neurol 2003;250:806-9

8. Suneetha S, Sigamoni A, Kurian N et al.The development of cutaneous lesions during follow-up of patients with primary neuritic leprosy International Journal of Dermatology 2005, 44; $224-229$

9. Guilloton L, Drouet A, Combemale P, Cruel T, Dupin M, Ribot C. Neuritic leprosy disclosed by reversal reaction. Rev Neurol (Paris) 2002;158:84-6.

10. Skacel M, Antunes SL, Rodrigues MM, Nery JA, Valentim VD, Morais RP, et al. The diagnosis of leprosy among patients with symptoms of peripheral neuropathy without cutaneous lesions: A followup study. Arq Neuropsiquiatr 2000;58:800-7

11. Mishra B, Mukherjee A, Girdhar A et al Neuritic leprosy: further progression and significance. Acta Leprol 1995; $9:$ 187-94.

12. Girdhar BK. Neuritic leprosy. Ind J Lepr 1996;68:35-42.

13. Garbino JA, Marques Jr W, Barreto JA et al. Primary neural leprosy: systematic review. Arq Neuropsiquiatr. 2013;71(6):397-404 


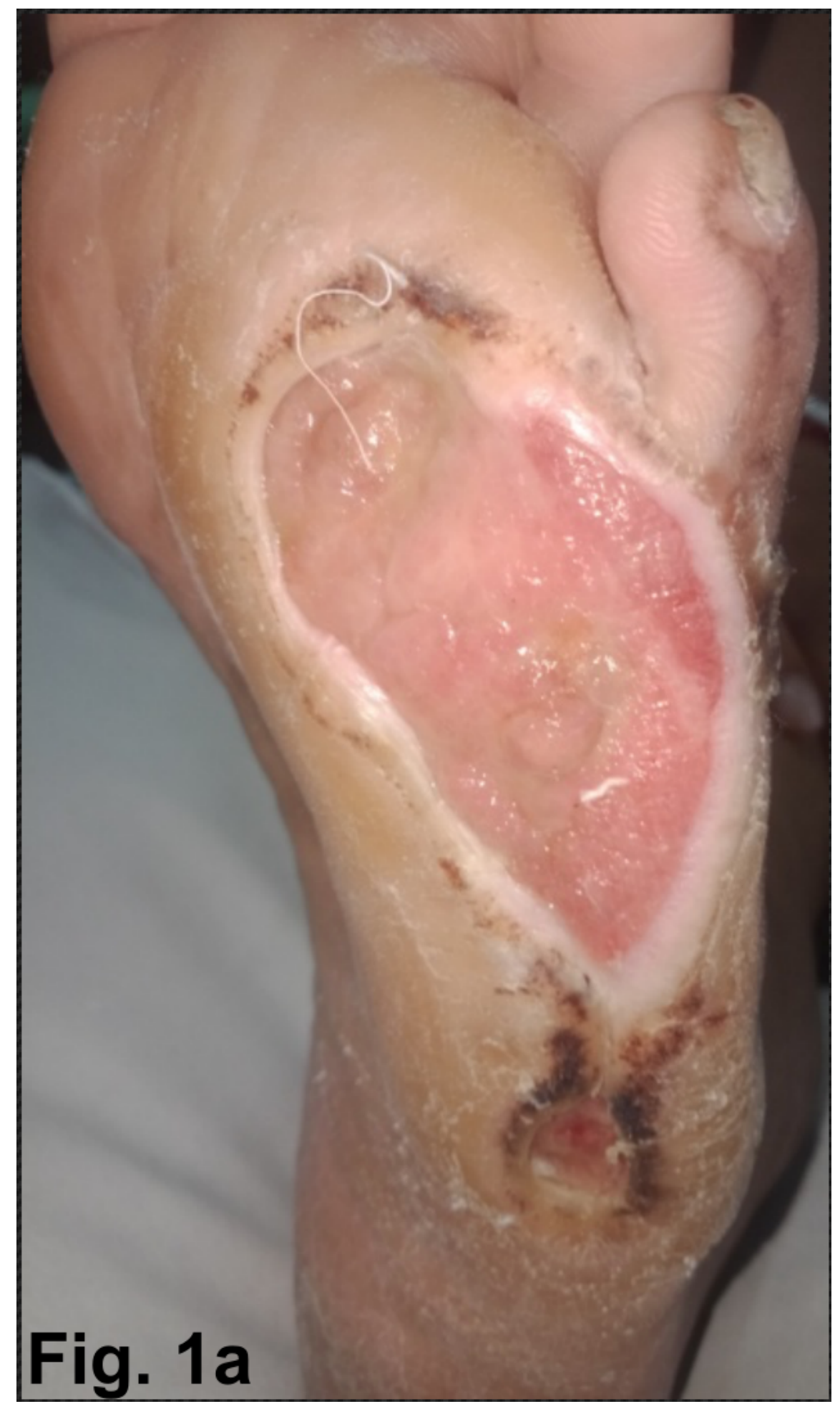




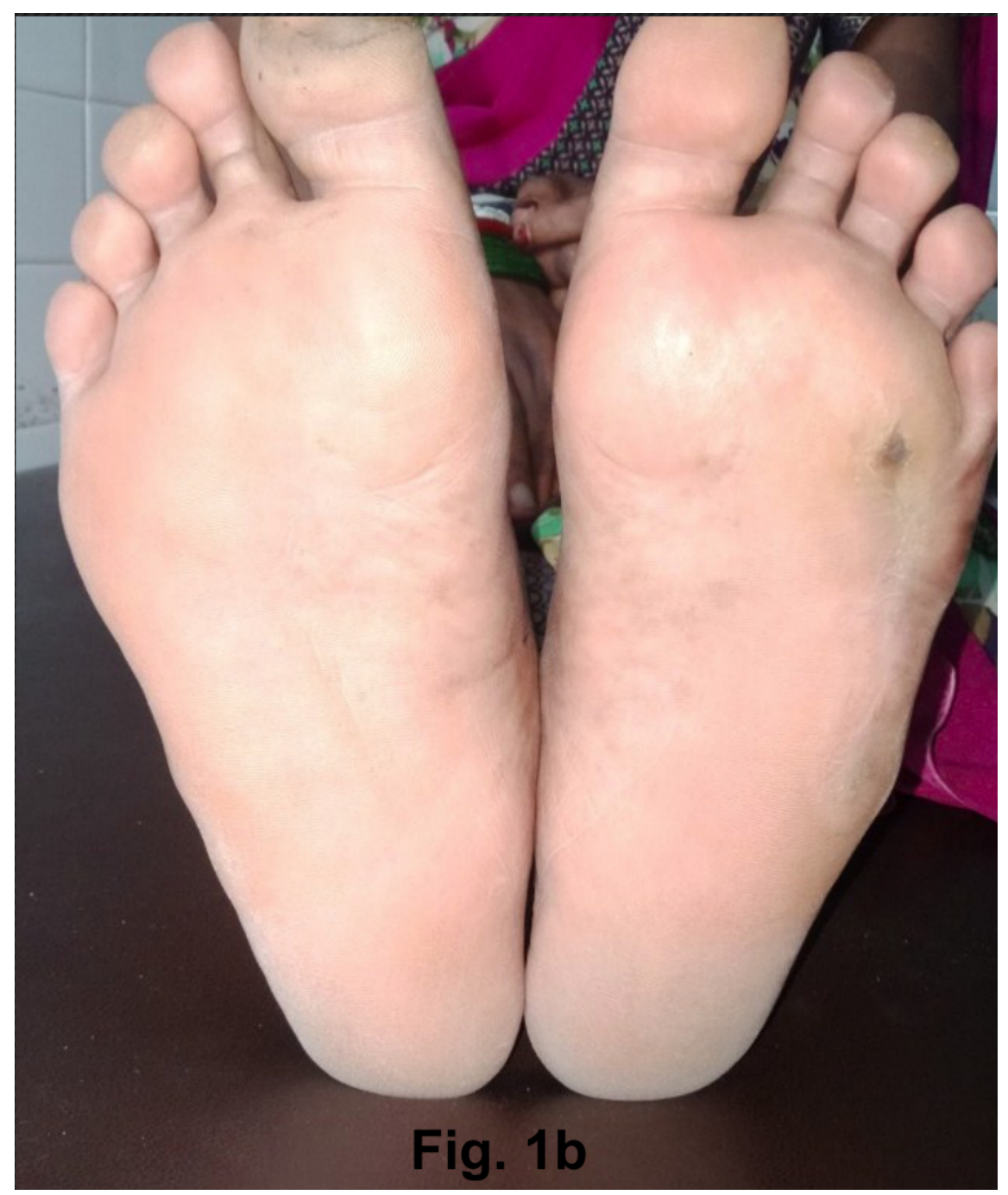




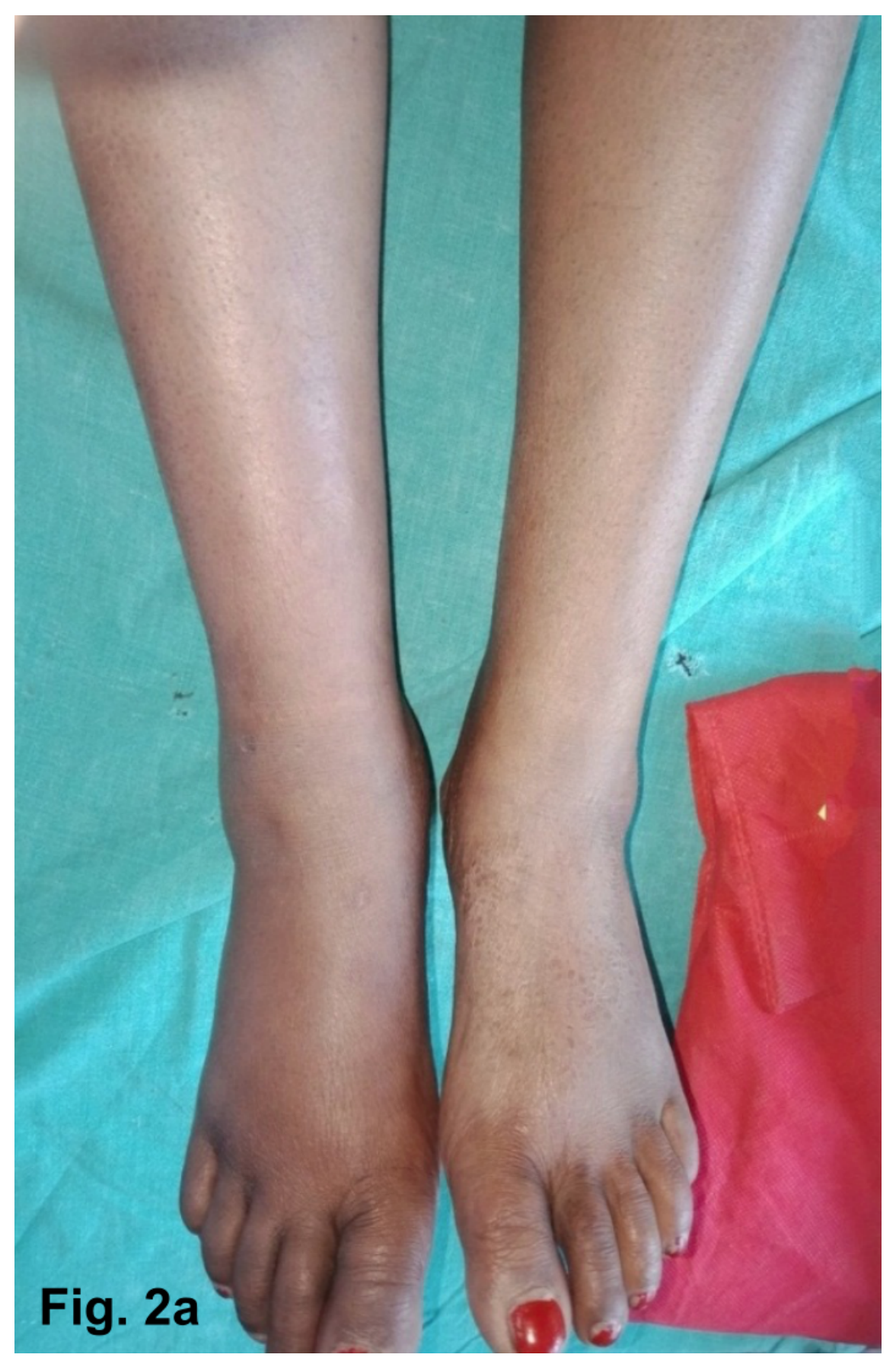




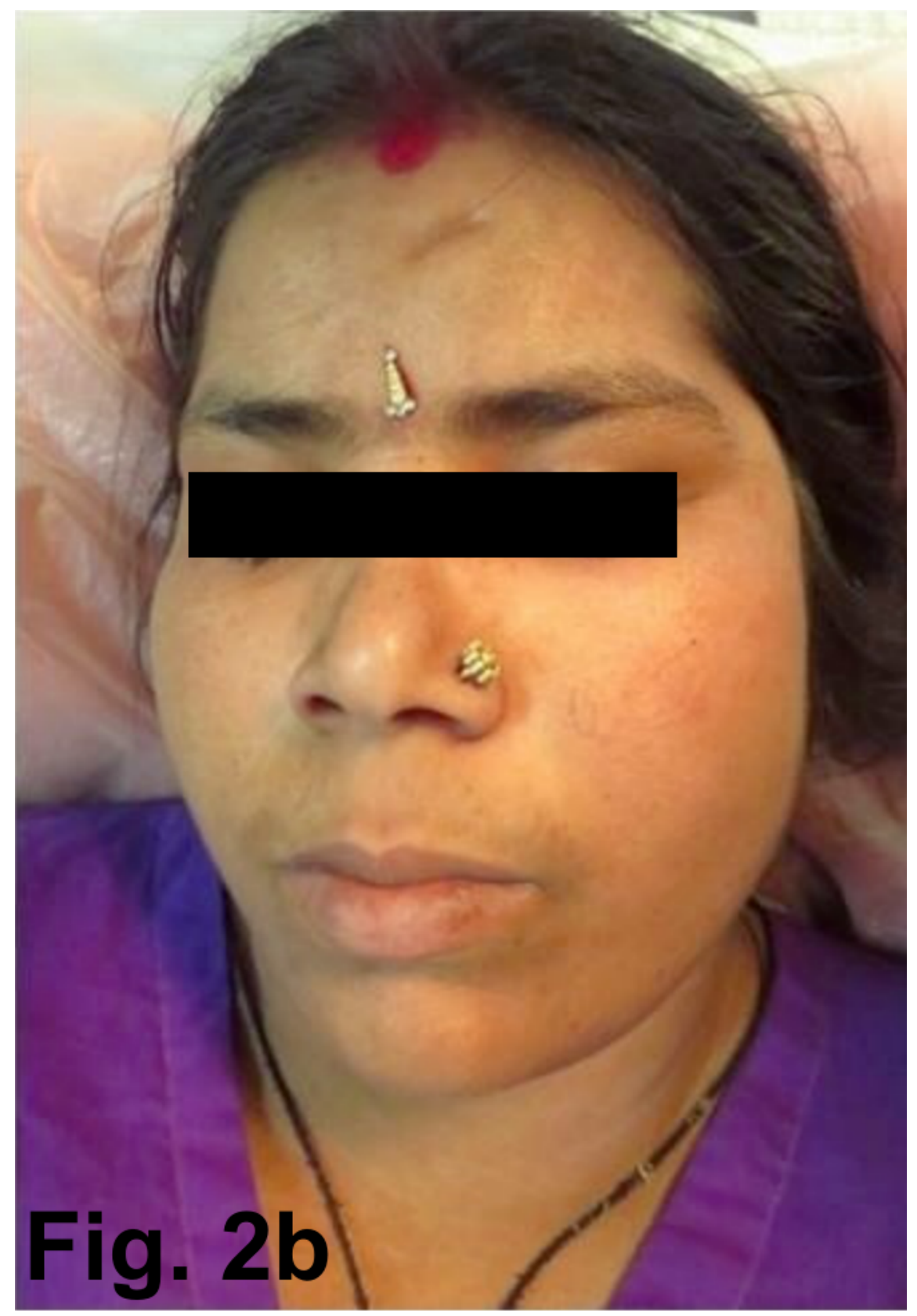




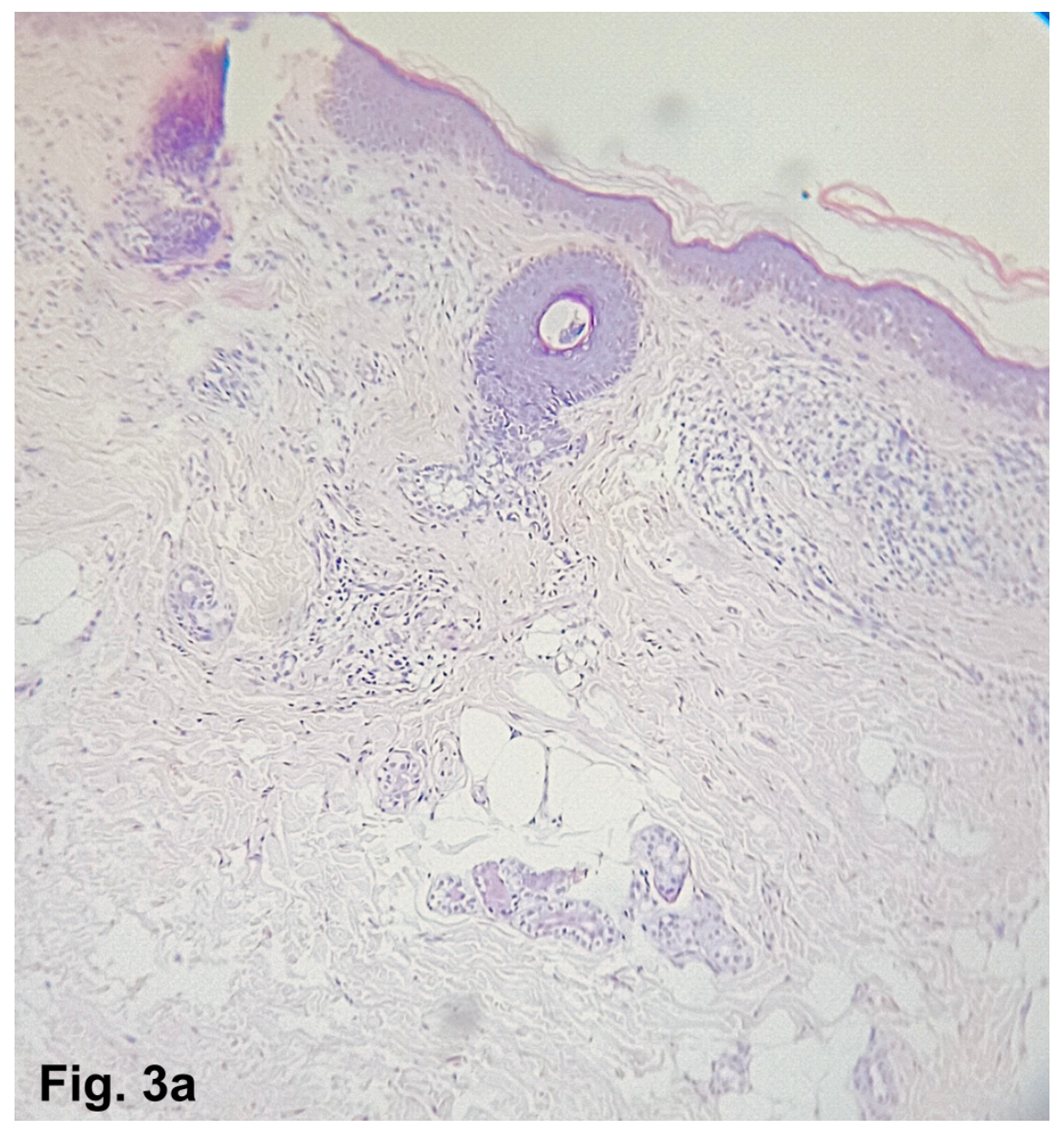




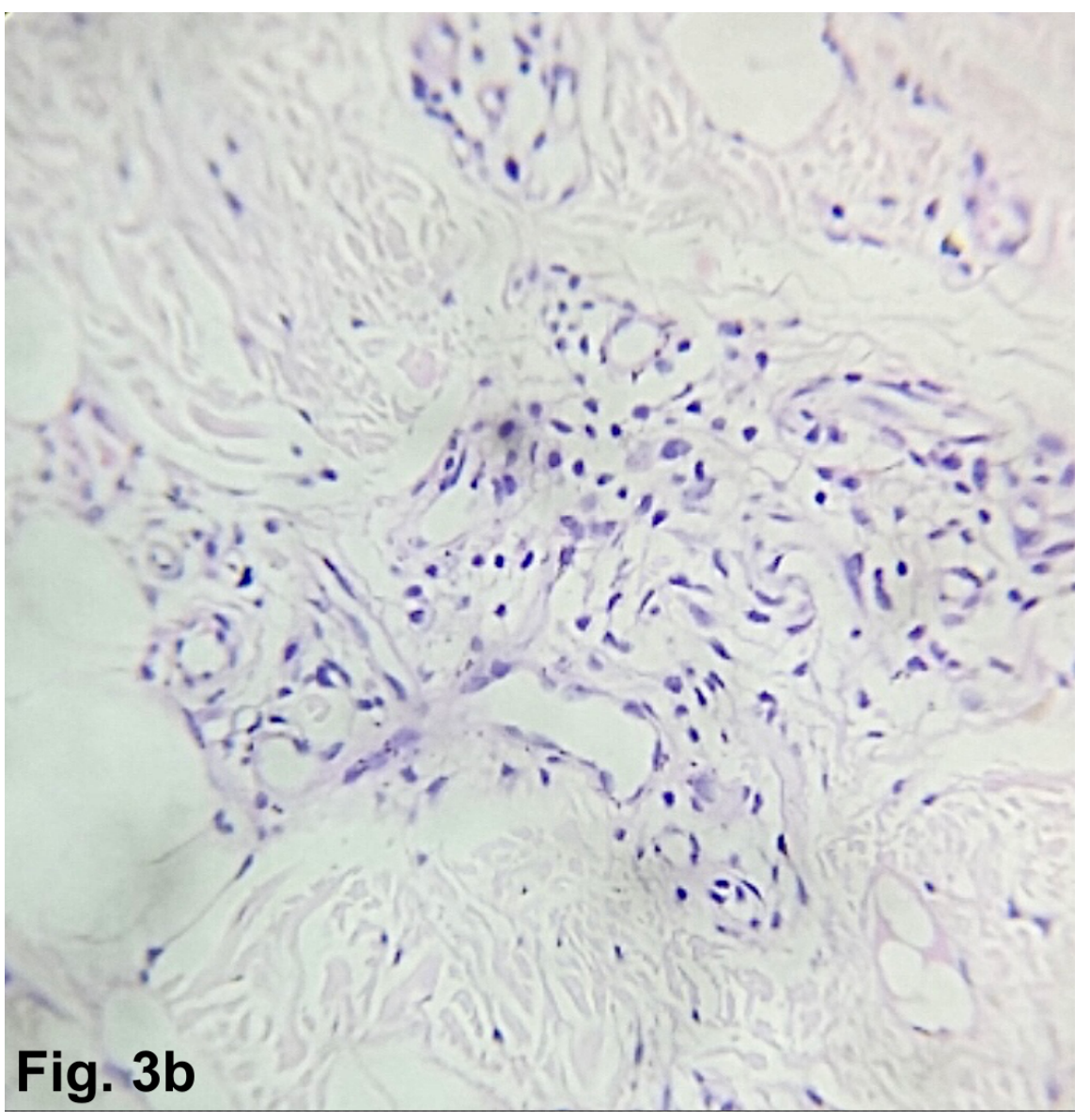




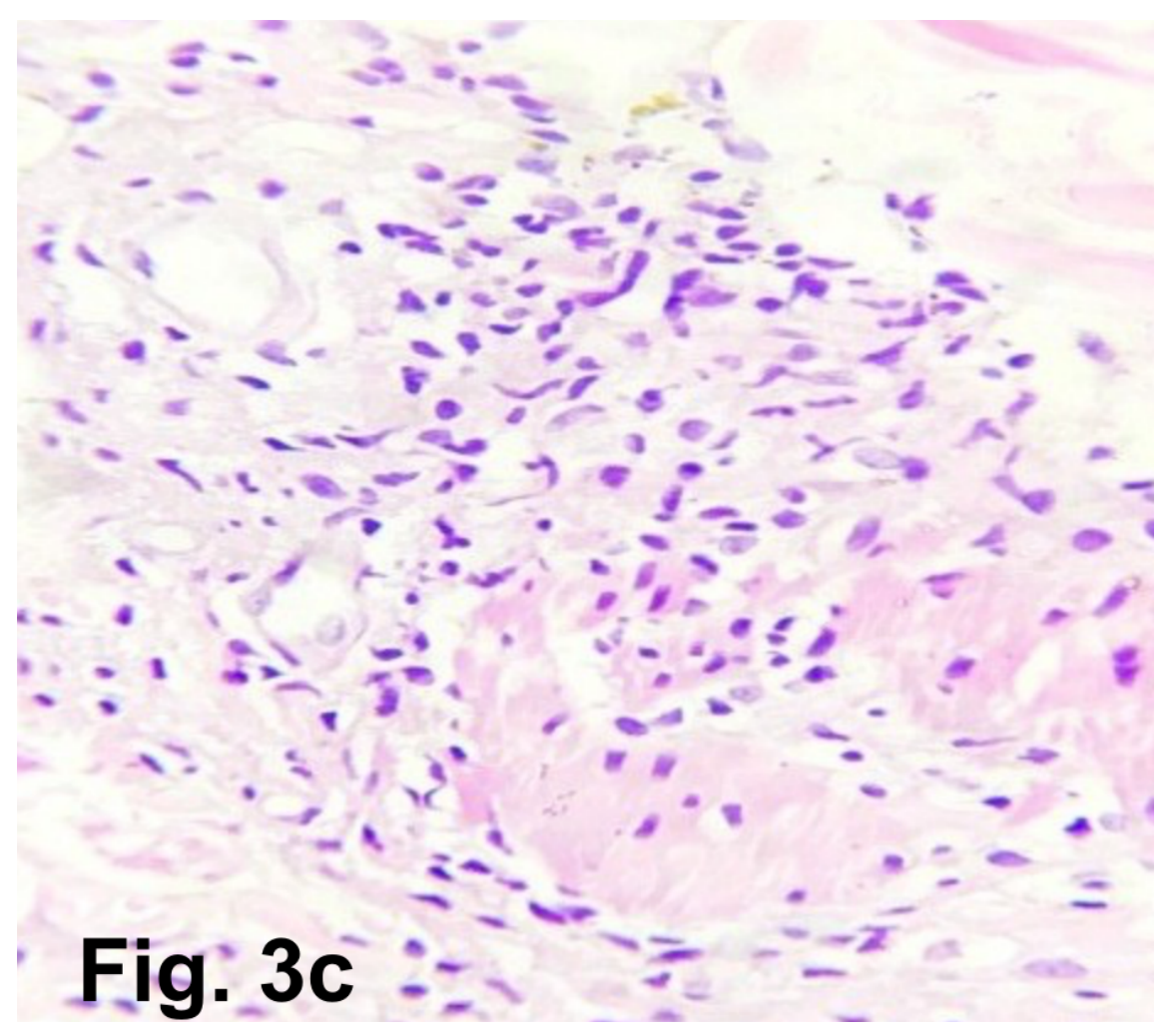




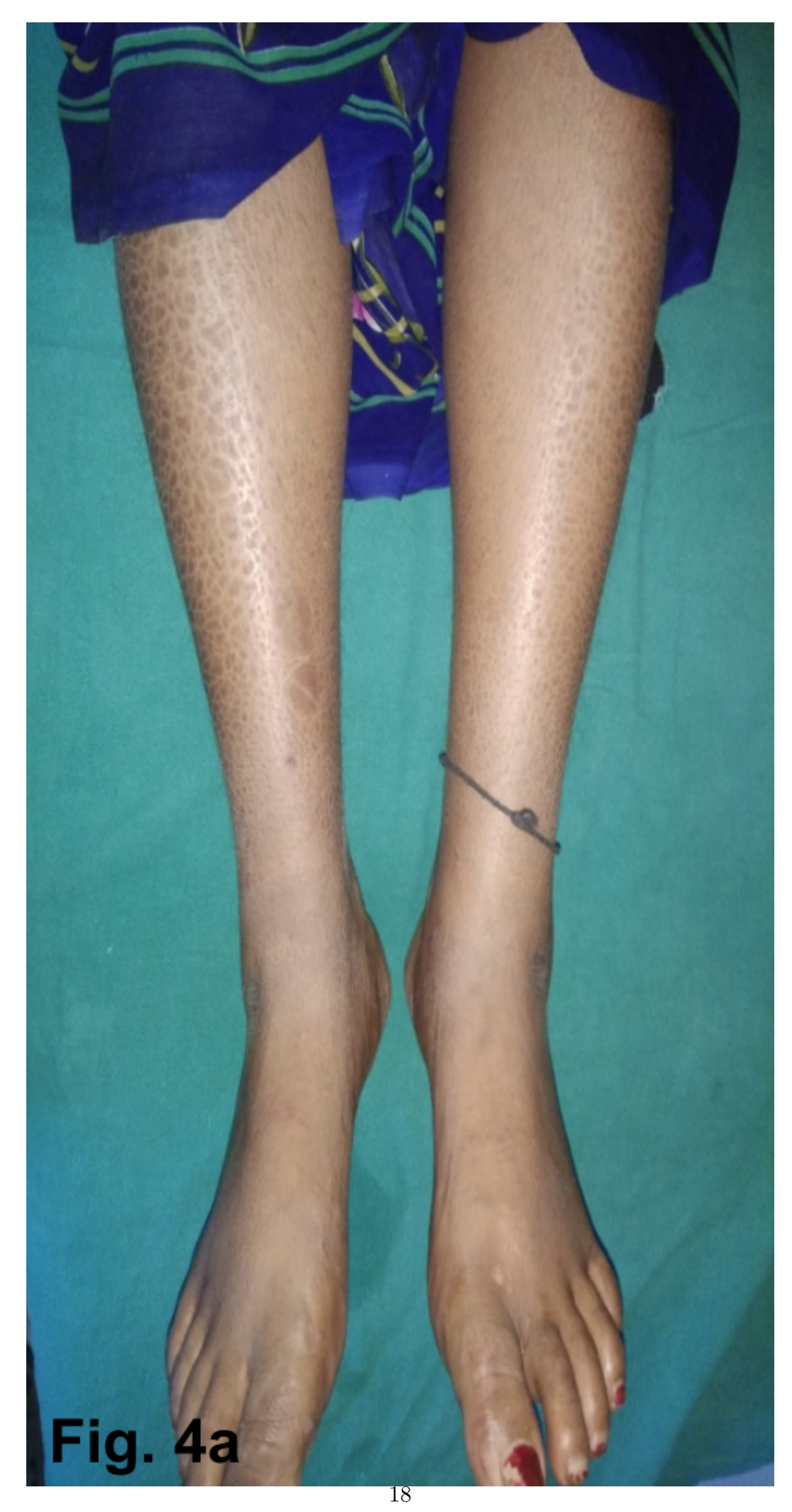




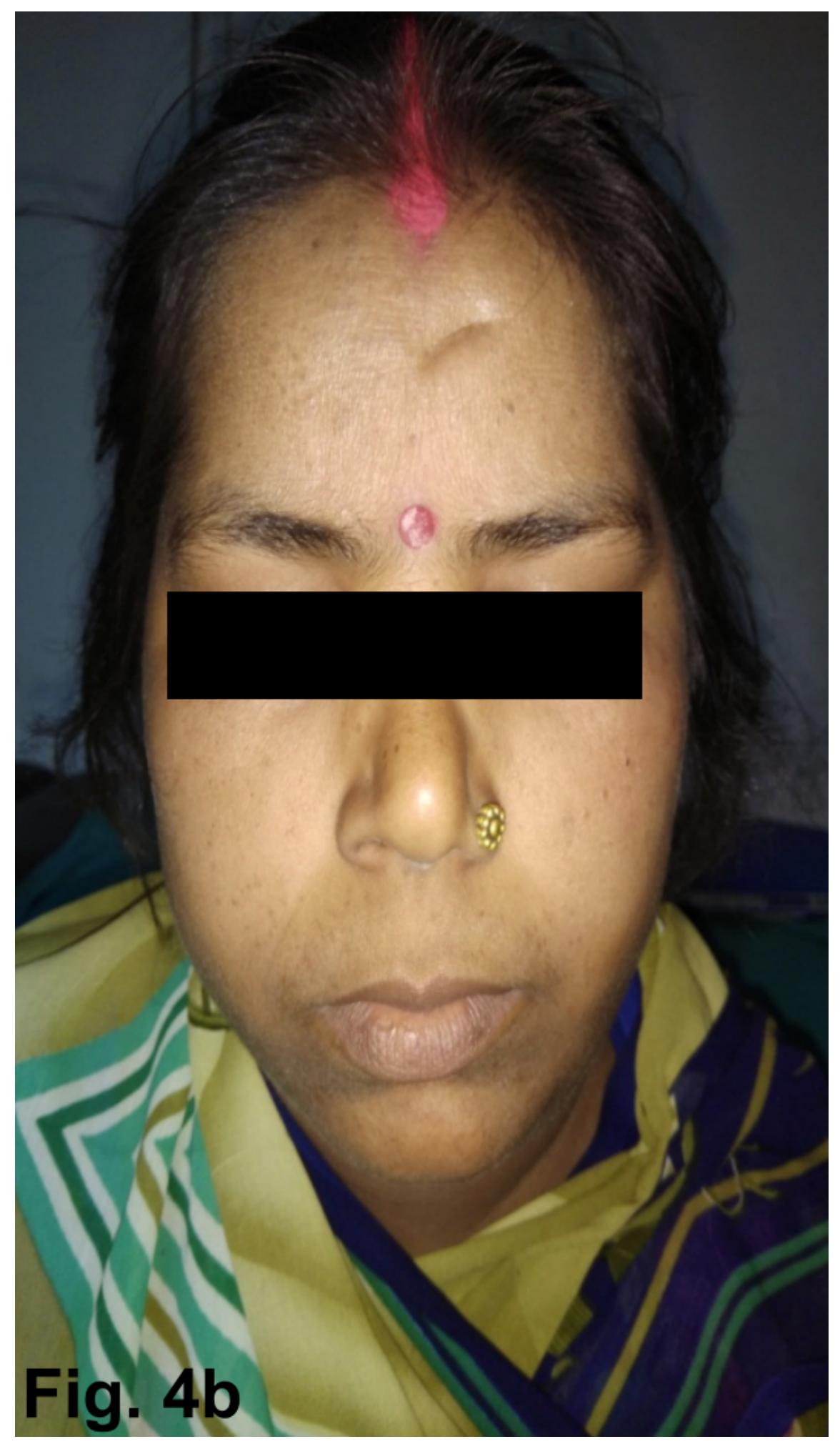

